\title{
The Treatment Role of the Plastic Nail Guard for Ingrowing Toenails
}

\author{
DG Robertson, PJ Parker
}

Major DG Robertson MRCGP DCH, RAMC General Practitioner

Middle Wallop Medical Centre,

2 (Training) Regiment, Army Air Corps,

Hants, SO20 8DY

Lt Col PJ Parker

FRCSEd(Orth),

RAMC

Consultant

Orthopaedic Surgeon

Orthopaedic

Department,

$\operatorname{MDHU}(\mathrm{N})$,

Friarage Hospital,

Northallerton,

N. Yorks. DL6 IJG

\begin{abstract}
Summary
An illustrative case of bilateral ingrowing toe-nails highlights the practical advantages of the use of the plastic nail guard (PNG). Insertion of the PNG is inexpensive and is easy to learn and perform. The technique is described and discussed. Its recurrence rate compares favourably with simple avulsion and wedge resection.
\end{abstract}

\section{Case Report}

A healthy 30-year old soldier presented with acute pain in both great toes. He had described niggling discomfort in the lateral nail fold area for some weeks previously. Increased physical activity may have precipitated the acute deterioration. The patient reported that his footwear was changed regularly and was normally comfortable. There was no past history of treatment for ingrowing toe-nails. In the days leading up to the appointment the patient had tried to relieve the discomfort by "cutting into the corners" when nailtrimming. This may have inadvertently aggravated the problem.

Examination showed that both feet were biomechanically normal with no evidence of any fungal infection of the nails or feet. The lateral nail folds of both right and left great toe-nails were red and swollen with marked tenderness and a slight purulent discharge from the corner of the nail. There was no granulation tissue obstructing the nail.

After informed consent on the treatment options of nail avulsion, wedge resection or

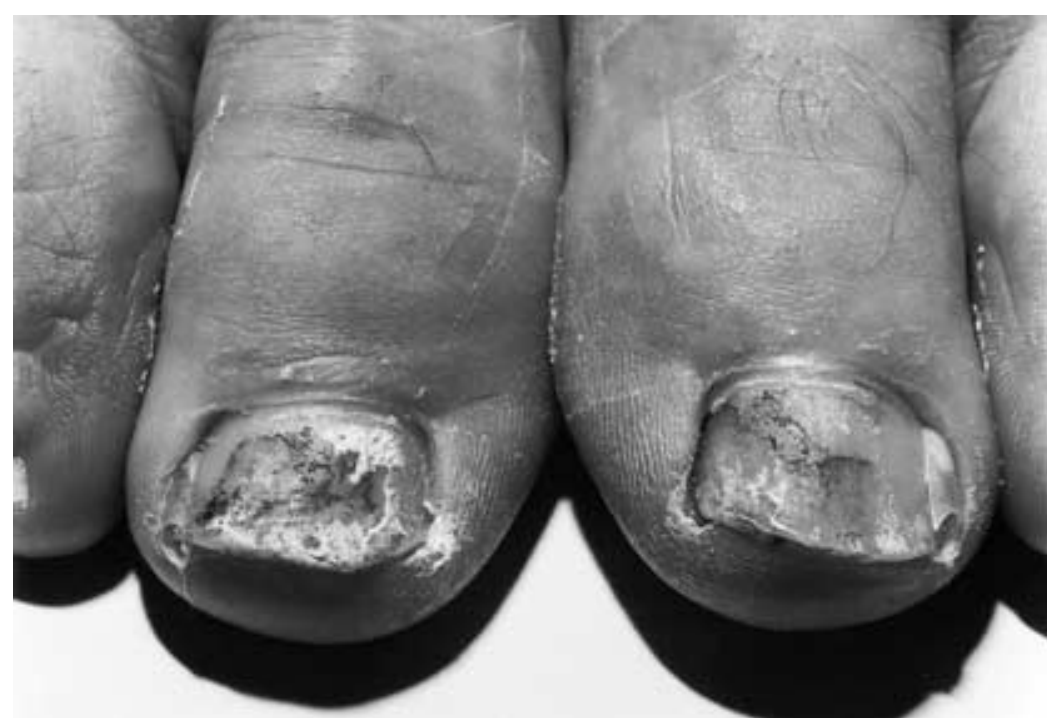

Fig 1. Bilateral Plastic Nail Guards (PNGs) seen from above. plastic nail guard (PNG), the patient opted for bilateral PNG insertion as described below. When reviewed at 48 hours the patient was mobile and the pain from the offending ingrowing toe-nail had significantly lessened. Only some slight discomfort from the PNG itself was reported and this settled over the next 72 hours. 5 days after the index procedures, the soldier and was able to run and play squash without pain. The PNG's were found to be comfortably in place at 3 weeks (Figures 1 and 2). The PNG's were removed at 6 weeks. At the same time the patient was reminded of the importance of future preventative measures such as correct nail trimming and avoidance of tight fitting footwear, especially during sporting activities. At 6 month review there had been no recurrence.

\section{Technique}

(A) The affected toe-nail is cleansed with antiseptic solution and a ring block of local anaesthetic instilled with a 23 gauge blue needle ( $1 \%$ plain lignocaine is commonly used, but $0.5 \%$ bupivicaine has the advantage of a more prolonged analgesia). A rubber tourniquet is then applied around the toe base.

(B) The PNG (or gutter) is harvested from either an 12-14 gauge Medicut cannula (Argyle, UK) or the needle sheath from a 21 gauge green Butterfly (Venisystems, Abbot, Ireland). If the cannula is used, the tapered end portion is discarded. The PNG is now simply split longitudinally for $3-4 \mathrm{~cm}$.

(C) The Medicut needle introducer may be used to peel the soft tissue gently away from the lateral nail edge. This has the effect of creating a channel, thus clearing the way for easier insertion of the semi-rigid plastic guard (Figure 3). The PNG is then pushed firmly along the lateral nail fold until the end is firmly in place adjacent to the germinal matrix. Usually $2-3 \mathrm{~cm}$ of nail guard is required to completely cover the nail spicule. The PNG can then be trimmed flush with end of the nail using a scalpel (Figure 4). Any excess granulation tissue can be excised and/or cauterised with a silver nitrate stick. If infection is evident at the time of the procedure, then a short 3-5 day course of flucloxacillin is prescribed.

(D) The PNG is secured. Zinc oxide tape 


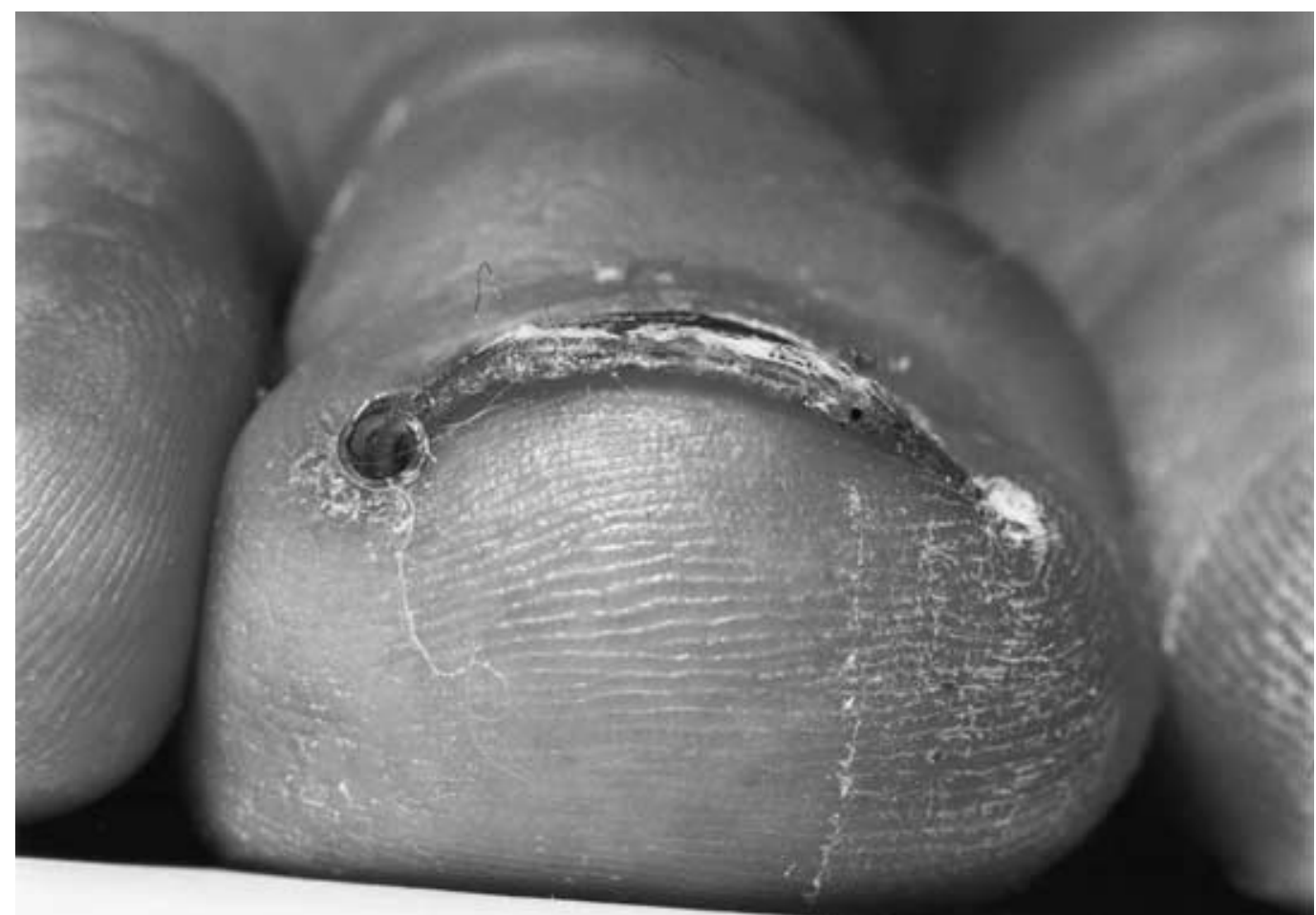

Fig 2. The PNG viewed end-on in the sulcus of the right great toenail; The mode of soft tissue protection can be very clearly seen.

is used to hold a small pledget of cotton wool over its trimmed end. The patient is advised to wash the toenail each day in plain soapy water and change the tape cover, taking care not to disturb the PNG. The PNG is left in place for 6 weeks and then simply removed with forceps.

\section{Discussion}

Ingrowing toe-nails are common, particularly amongst young adults and those participating in physical training and sport - a subgroup common to the Armed Forces. $73 \%$ of cases occur between the ages of 12 and 30 (1). Three disease stages have previously been described, providing a useful guide to which treatment options are most suitable. These are: Stage one -

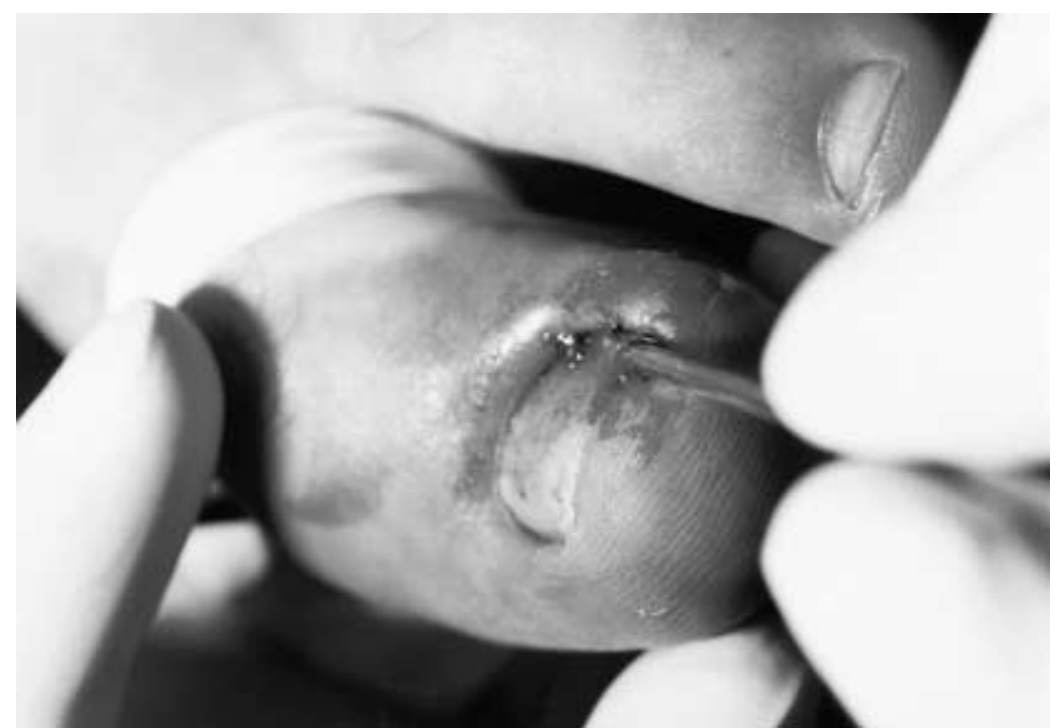

Fig 3. Where the lateral nail sulcus tissues are particularly tight, the Medicut needle introducer can be used to create a channel and make PNG insertion easier.
Erythema, slight oedema and pain when pressure is applied to the lateral nail fold. Stage two - Increased stage one symptoms, drainage and infection. Stage three Magnified stage one symptoms, presence of granulation tissue and lateral wall hypertrophy (2).

For most general practitioners with only a basic tutelage in minor surgery, the treatment options for acute ingrowing toenails are largely limited to antibiotics, simple total avulsion and cotton wool splints (3). For those other GPs who have acquired additional experience and skills in minor surgery, wedge resection with or without partial phenol germinal matrix ablation (PGMA) can be successful in stage 2 or 3 disease where the problem is more severe or recurrent (4).

There is another very useful, though now neglected technique, which can be used to treat stage one (and early stage two) disease. This involves the insertion of a small device along the nail fold to protect the skin from the offending nail edge. This was first described by Newman in 1949 (5). During WW2, he cut and bent pieces of used grapefruit juice cans into "steel nail plates" and used them as a "lateral nail groove protector device" on ingrowing toe-nails in troops aboard ship in advance of Operation 'Husky' - the amphibious landings on Sicily in 1944. The steel nail plate was fairly bulky, however, and required a full thickness incision along one side of the lateral nail fold.

Newman also coined the fundamental treatment principle underpinning the use of splinting methods for ingrowing toenails:- 


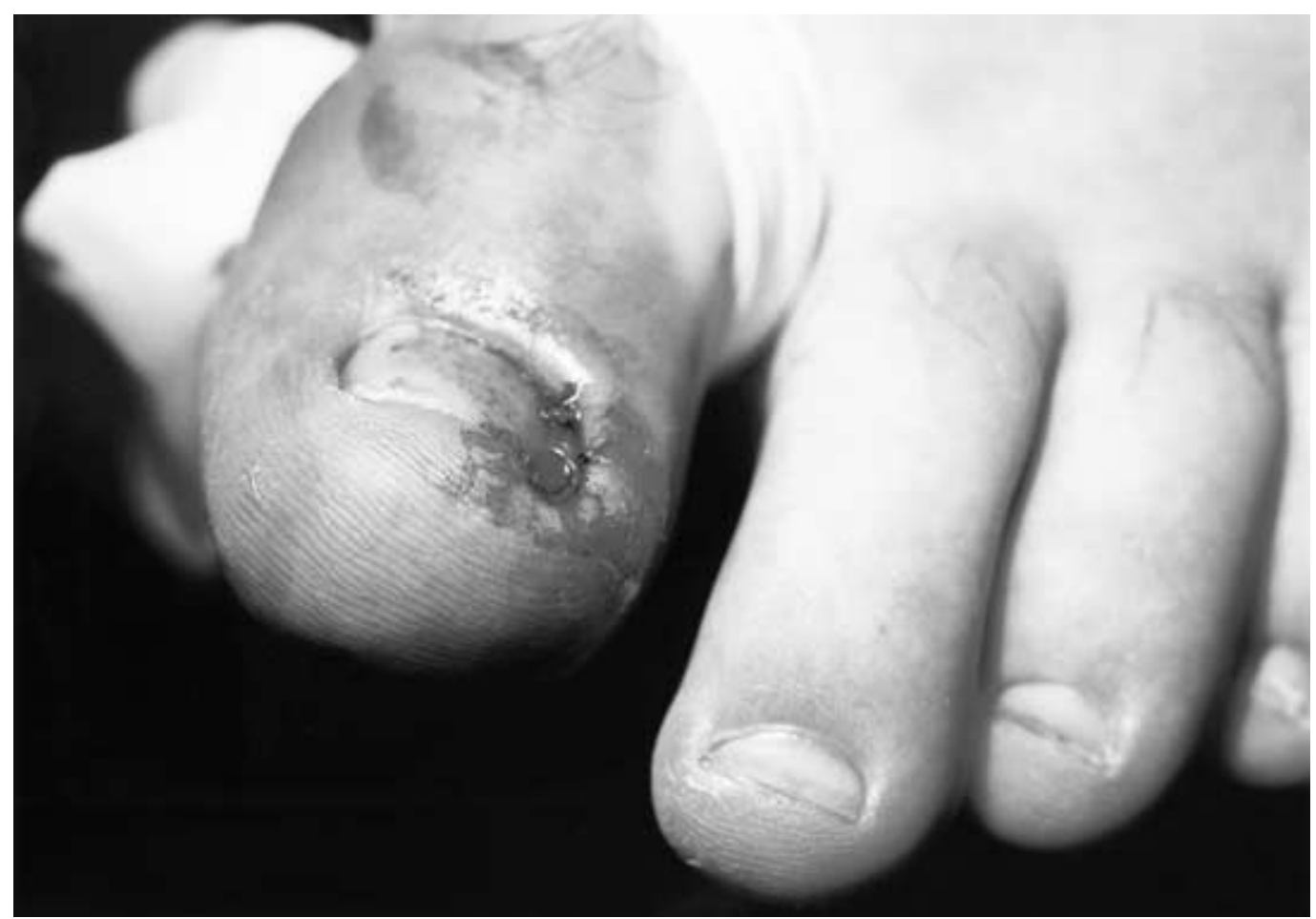

Fig 4. The immediate post operative result in the left great toenail viewed end-on.

"..to re-establish the lateral nail sulcus, and thus to provide the nail with an open channel along which its growth may proceed in a healthy and unobstructed fashion until the nail end is free from any adjacent impeding soft tissue and skin".

Other devices followed, but all relied on the same basic principle of nail sulcus protection $(6,7,8)$. Wallace designed and commercially produced his own 'nail gutter' device, but this is no longer available. An illustrated, step by step description of the technique of PNG insertion has been recently published (9). The use of either (a) the non-tapered section of the plastic cannula sheath from a $2.6 \mathrm{~mm}$ (12 gauge) Argyle Medicut, or (b) the needle sheath from a gauge 21 Butterfly, overcomes the need for any special equipment.

Previous research has tried to compare the PNG with wedge resection and phenol germinal matrix ablation (PGMA) (8). Effective and clinically relevant comparisons were found to be difficult mainly due to the fact that, in their study, PGMA was performed by experienced and skilled surgeons, a situation often far removed from every day primary care and casualty departments.

Nevertheless, it was found that the risk of recurrence for the PNG was 33\%, half that of simple avulsion (8). More recently, physicians in Germany adapted the gutter technique described by Wallace for use in an out patient department (10). The authors described their use of a longitudinally split drainage tube $(2.64 \mathrm{~mm}$ diameter, SteriMed, Germany). The cost-effectiveness of this mode of treatment is reflected by their findings: 62 patients were treated over a five year period and zero recurrences were reported, though the methods of follow up were not described (10). The main practical advantages of the PNG are therefore at the first presentation of an uncomplicated ingrowing toe-nail at stage one or two disease and are summarised below (Table 1). The main benefit for service personnel is the potential for early mobilisation; soldiers should be able to return to their normal duties within 24 hours of the procedure, and this is without the need to attend the practice nurse or combat medical technicians for dressings. In addition, treatment is simple, primary care based and independent of local outpatient waiting lists.

Table 1. The Main Advantages of the Plastic Nail Guard

- Simple "See One, Do One" minor surgical training and skill required.

- Cheap and quick to perform.

- Suitable for use in field conditions or in primary care

- Active infection is not a barrier to the procedure.

- Recurrence rate half that of simple avulsion.

- Relief of pain within 12 hours.

- Does not undermine other treatment options.

- Affords an early return to sporting activity.

Recurrent or refractory cases are best referred for treatment to a qualified surgeon or specially trained and skilled GP colleague. In experienced hands, partial or total PGMA was $97 \%$ successful (8), and a concise 16-step guide for those interested in 
performing partial PGMA in conjunction with wedge resection is available (4).

In summary then, there is a good argument for greater use of the PNG in service personnel in the primary care setting. Prompt pain relief free of dressings, a return to normal activities within 24 hours and a resumption of sport within a few days are the main attractions offered by this procedure. That said, there is a clear opportunity to investigate this treatment further. At this stage the authors expect to produce a teaching video of the PNG technique. It is then planned to follow this up with a prospective randomised trial within a wholly military population. The authors (DGR) are keen to hear from practices that are interested in the application and study of the PNG.

\section{Conclusion}

Clear descriptions of the successful application of lateral nail fold protector devices date back to the Second World War. The Plastic Nail Guard is a useful and easy treatment option for uncomplicated acute ingrowing toe-nails. Its use should be commended in general practice. An instructional video on the PNG insertion technique is planned, followed by further prospective research in a military population.

\section{References}

1. Murray WR, Bedi BS. The surgical management of ingrowing toenails. Br F Surg 1975; 62: 409-12.

2. Zuber TJ, Pfenninger JL. Management of Ingrown Toenails. Am Fam Physician; Jul 1995; 52(1): p181190.

3. Lloyd-Davies RW, Brill GC. The aetiology and out-patient management of ingrowing toe-nails. $\mathrm{Br}$ 7 Surg 1963; 50: 592-7.

4. Sambandan S. Management of ingrowing toenail Update; June 24 1999: 1267-69.

5. Newman RW. A simplified treatment of ingrown toenail. Surg Gynecol Obst 1949; 89: 638-9.

6. Dagnall JC. Methyl methacrylate splint for ingrown toenails. Br Chir fournal 1965; 30: 100.

7. Ilfeld FW, August W. Sulcus protector for ingrown toenails. Orthop Clin N.America 1974; 5: 95.

8. Wallace WA, Milne DD \& Andrew T. Gutter treatment for ingrowing toenails. BMF 1979; 2: 168-71.

9. Robertson DG, Parker PJ. Plastic nail guard for ingrowing toenails. Update; March 19 1997: 383-85.

10. Schulte KW, Neumann NJ \& Ruzicka T. Surgical pearl: Nail splinting by flexible tube - A new noninvasive treatment for ingrown toenails. $\mathcal{F} \mathrm{Am} \mathrm{Acad}$ Dermatol 1998; 39 (4:1): 629-30. 